LA-UR $95 \rightarrow 20$

$\operatorname{con}=950220-2$

AUTHOR(S):

ELIZABETH A. COOPER

HARRIET KUNG

MICHAEL NASTASI

SUBMITTED TO:

paper as proceedings to IBMM conference, Canberra Australia

Feb 5-10, 1995, to be published in Nucl. Mat. and Meth. in

Physics B

By acceptance of this article. the pubtisher recognizes that the U.S Government retains a nonexclusive. royalty-tree license to publish or reproduce the published form of this contribution. or to allow others to do so. for U S. Government purposes.

The LOS Alamos National Laboratory requests that the publisher identlly this article as work performed under the auspices of the U.S. Department of Energy

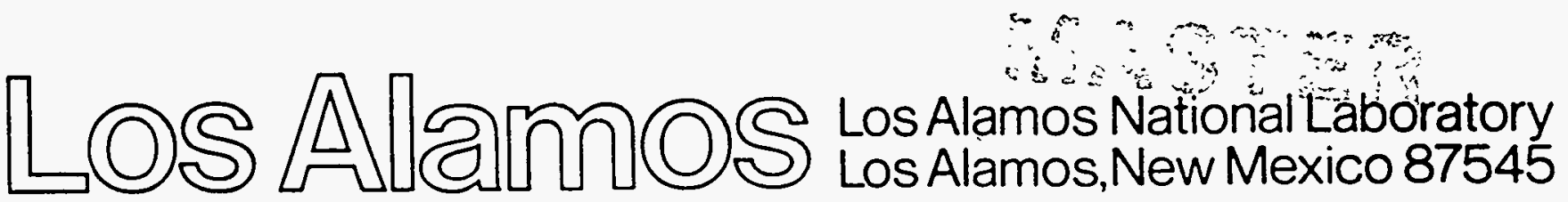




\section{DISCLAIMER}

Portions of this document may be illegible in electronic image products. Images are produced from the best available original document. 


\title{
Systematic Study of the Ion Beam Mixing of Oxide Markers into Alumina
}

Elizaioth A. Cooper, Harriet Kung, and Michael Nastasi

Los Alamos National Laboratory, Materials Science and Technology Division, Los Alamos, NM 87544

\begin{abstract}
We have completed a systematic study of ion beam mixing of thin marker layers into amorphous alumina. The degree of mixing was found to be controlled by thermodynamic factors, the nature of the marker (oxidation state), and matrix crystallinity. Ballistic mixing was observed for all markers, but the mixing of some oxide markers exhibits a thermally activated regime at higher temperatures. The experiments were conducted from a low temperature of $-170^{\circ} \mathrm{C}$ to a maximum temperature of $750^{\circ} \mathrm{C} .210$ $\mathrm{keV}$ Ar was used to ion beam mix the marker layer at the various temperatures. The marker spreading was analyzed using RBS.

The mixing of one marker $\left(\mathrm{Fe}_{2} \mathrm{O}_{3}\right)$ into crystalline alumina (sapphire) was compared to that of the amorphous alumina. It was found that the marker mixed asymmetrically into the two matrix materials, with a higher degree of mixing into the amorphous matrix. TEM cross-section results verify that there is a preference for the marker to mix into the amorphous alumina layer preferentially to the crystalline layer.
\end{abstract}

\section{Introduction}

The study of Ion beam mixing of layered compositions is important in two regards: first, there is the potential of alloying the layers into a new functionally different composition [1] and, secondly, from a fundamental aspect, it is important be able to anticipate the potential damage due to degradation of the layer structure that could be caused in these materials due to a radiation environment. Typically, at very low 
temperatures, the radiation induced marker spreading is independent of temperature and is proportional to dose; this constitutes the so-called ballistic mixing regime. In some mixing systems, however, there are one or more thermally activated regimes in which the degree of marker mixing into the matrix increases exponentially as a function of temperature, but with activation energies typically much less than $1 \mathrm{eV}$. [2] This low activation energy is indicative of radiation enhanced diffusion (RED). An example of this is shown in Fig. 1 for results we obtained for the mixing of an iron-oxide marker into an amorphous alumina matrix $[3,4]$ the first study of this kind that demonstrates that the thermally activated regimes can exist in ceramic marker systems. In the system shown in Fig. 1, two thermally activated regimes are observed, as well as the low temperature ballistic regime. For the purpose of determining the activation energies, both the thermal mixing and ballistic mixing components have been subtracted from the marker spreading in this plot. A good review of processes in ion beam mixing can be found in $\operatorname{Ref}[2]$ and $\operatorname{Ref}[5]$.

Our interest in the ion beam mixing of thin marker layers in ceramic systems is motivated by the fact that layered oxides are technologically important materials for fusion reactor applications and very little work has previously been done to examine the radiation induced layer mixing in these materials, especially as a function of temperature. Extensive work has been completed in metal and semiconductor systems (see for example, Refs [6][10]. Many ion beam mixing studies in ceramic systems are summarized in Table 1 with references. We have included some covalently bonded non-oxide (nitride and carbide) ceramics to cover the range of ceramic mixing systems that have been explored. The review of oxide systems in the table is divided into thin film marker studies and bilayer configuration studies.

Ion beam mixing in oxide systems has not been investigated until very recently and has been reviewed by McHargue [5] and are summarized in Table 1. So far, only ballistic (cascade or recoil) mixing has been observed for pure metal markers in alumina. Temperature dependent bilayer mixing of $\mathrm{Cr}_{2} \mathrm{O}_{3}$ and $\mathrm{ZrO}_{2}$ into alumina by Joslin et al. 
[12] [13] showed no detectable mixing in either system at $25^{\circ} \mathrm{C}$, but a small a amount of ballistic mixing in both systems at $80^{\circ} 9^{\circ} \mathrm{C}$. The first indications of thermally assisted ion mixing were reported for $\mathrm{Fe}_{2} \mathrm{O}_{3}$ markers in $\mathrm{Al}_{2} \mathrm{O}_{3}$ [6][7]. This motivated us to systematically explore the ion beam mixing of other marker systems into alumina based on thermodynamic arguments, mainly solubility and compound formation as a function of temperature. We also investigated the effect of matrix structure (amorphous vs. crystalline) on the degree of marker spreading for the iron oxide marker [25].

\section{Experimental}

\section{Sample Preparation}

Thin film marker samples were produced by electron beam deposition. We have chosen a thin marker configuration to avoid resolution limitations, heat of mixing effects, and excessive surface roughening due to sputtering for the higher doses required to observe mixing of the bilayers. Two configurations were used and will be discussed in more detail later. These two configurations are shown schematically in Fig 1. Typical

marker layer thickness was $35-140 \AA$ (depending on the RBS yield for each element) and the upper amorphous alumina layer was usually about $1000 \AA$ thick (see [11] and [25]). The deposited amorphous alumina had a measured density of $2.55 \mathrm{gm} / \mathrm{cc}$, compared to $3.98 \mathrm{gm} / \mathrm{cc}$ for the sapphire substrate. The first configuration (Fig. 2(a)) has an amorphous alumina layer above and below the marker layer; this is referred to as the am/am configuration later in this discussion. The second configuration (Fig. 2(b)) has an amorphous alumina top layer, a marker layer, and a crystalline alumina (sapphire) layer below the marker; this is referred to as the am/cryst configuration in the forthcoming discussion. The am/cryst configuration was used to test if the matrix density and degree of crystallinity would effect the marker spreading. The markers were ion mixed at constant temperatures $\left(-166^{\circ} \mathrm{C}-750^{\circ} \mathrm{C}\right)$ using $210 \mathrm{keV}$ Ar. The samples were in thermal contact with a temperature controlled $\mathrm{Ni}$ block during irradiation. To distinguish between mixing 
due to thermal effects only, control samples were places on the opposite face of the $\mathrm{Ni}$ block to be exposed to the same thermal conditions as the ion beam mixing samples.

Based on TRIM calculations, dpa at the marker depth ranged from 12 to 65 for doses ranging from 1.25 to $7 \times 10^{16} \mathrm{Ar} / \mathrm{cm}^{2}$. A majority of the experiments were run for a dose of $2.5 \times 10^{16} \mathrm{Ar} / \mathrm{cm}^{2}$ resulting in $23 \mathrm{dpa}$ at the marker depth. For the amorphous/crystalline experiments, dose was held constant, resulting in a calculated 23 dpa at the marker depth of $100 \mathrm{~nm}$.

$R B S$

All post-irradiation samples were examined using Rutherford Backscattering Spectroscopy (RBS). The spreading of the marker layer was determined by fitting the RBS peak with a gaussian (in the case of the am/am configuration) or a superposition of two half gaussians (see[25]) for the am/cryst configuration to fit the asymmetric spreading. The activation energy for the systems that exhibited high temperature radiation enhanced mixing was determined by subtracting the ballistic and thermal contributions from the marker spreading and assuming an Arrhenius relationship for the activation.

\section{TEM}

Pre- and post-irradiation samples were prepared in cross-section, thinned, and ion milled to electron transparency. The TEM results presented in this paper are for samples with the am/cryst configuration shown in Fig. 2(b).

\section{Results and Discussion}

\section{Marker Oxidation State}

A comparison of the ion-beam mixing of iron metal markers and iron-oxide markers into amorphous alumina is shown in Fig. 3 (a) and 3(b), respectively, both for samples ion beam mixed at $625^{\circ} \mathrm{C}$ to a dose of $2.5 \times 10^{16} \mathrm{Ar} / \mathrm{cm}^{2}$. From this, it can be seen 
that there is a significant influence of the oxidation state of the marker on the ion beam mixing results [4]. This is demonstrated by the apparently complete lack of marker spreading for the Fe-metal in Fig. 3(a) compared to the broad symmetric spreading observed for the $\mathrm{Fe}_{2} \mathrm{O}_{3}$ marker in Fig. 3(b). It is true, in general, that in oxide mixing systems that the pure metal markers in alumina $\left(\mathrm{Al}_{2} \mathrm{O}_{3}\right)$ and silica $\left(\mathrm{SiO}_{2}\right)$ only demonstrate low-level ballistic mixing. This is shown in Table 1 for a literature survey of many systems. These results are consistent whether the experimental sample configuration is a thin marker or a bilayer.

\section{Crystallinity of Matrix}

Shown in Fig 3(c) is the RBS results for the am/cryst configuration ion beam mixed at $630^{\circ} \mathrm{C}$ to the same dose as the samples shown in Figs. 3(a) and 3(b). The RBS results show asymmetric mixing; there is more mixing into the surface (amorphous alumina) than into the sapphire substrate. The fitted results indicate that the activation energy for the thermally enhanced regime for the crystalline (sapphire) mixing was twice that for the amorphous mixing. These results are reviewed in Table 2.

To address the question of whether or not the difference in absolute degree of mixing was due to voids in the deposited amorphous layer, a cross sectional TEM study was undertaken to examine the nature of the as deposited sample, and also to make a secondary observation on the degree of marker mixing in the system. The results of the TEM study are shown in Fig. 4 for several sample conditions.

Figure 4(a) show the pre-irradiation cross-section for the am/cryst configuration.

The main observations seen for this sample are:

1) there are no voids in deposited amorphous alumina, even though the deposited density is very low,

2) there are some non-epitaxial crystalline regions in the as-deposited iron oxide, but it is mostly amorphous, 
3) the marker layer thickness is approximately $4 \mathrm{~nm}$, and

4) the surface (amorphous) alumina layer thickness is approximately $95 \mathrm{~nm}$.

Fig 4(b) shows a cross section for an am/cryst sample which was ion beam irradiated at $-145^{\circ} \mathrm{C}$ to a dose of $2.5 \times 10^{16} \mathrm{Ar} / \mathrm{cm}^{2}$. From this micrograph it can be seen that:

1) the end of range for implanted Ar is approximately $255 \mathrm{~nm}$; TRIM calculations estimate that this should be $250 \mathrm{~nm}$ using Kinchin-Pease approximations. This distance is well into the sapphire (originally crystalline) layer,

2) the originally crystalline sapphire layer has amorphized from the ion beam damage. The end of ion range is signified by transition from amorphous alumina to original crystalline alumina (sapphire) in this layer,

3) iron oxide marker layer has remained amorphous, and

4) little spreading observable for marker layer from the micrograph.

Fig. 4(c) shows an am/cryst sample which has only undergone a high temperature $\left(725^{\circ} \mathrm{C}\right.$ ) heat treatment in the ion beam irradiation chamber (a thermal control sample). Some observations from this micrograph are:

1) regions of gamma alumina have formed in the amorphous alumina (upper) layer,

2) the iron oxide layer has spread significantly $(15 \mathrm{~nm})$,

3) the sapphire-iron oxide interface has roughened,

4) occasional "blooming" of iron oxide into surface alumina layer can be seen, and the "bloomed" iron oxide has crystallized epitaxially with respect to the sapphire,

5) voids have formed in the marker layer after spreading (low density), reducing the density of the remaining iron-oxide, and

7) some parts of marker layer (other than the "bloomed" areas) have recrystallized epitaxially (with sapphire).

Finally, in Fig. 4(d), a cross-section for an am/cryst sample is shown which has been high temperature ion-beam mixed, at $625^{\circ} \mathrm{C}$, to a dose of $2.5 \times 10^{16} \mathrm{Ar} / \mathrm{cm}^{2}$. 
1) dark (electron backscattering) transition region in sapphire - amorphous

2) massive spreading of iron oxide marker ( $180 \mathrm{~nm}$ through dark layer, assuming $Z \mathbf{Z}$ contrast indicates iron)

3) epitaxial (with alpha alumina) iron oxide marker

4) no significant voids in iron oxide layer after mixing

5) surface alumina is nanocrystalline gamma alumina (no significant amorphous alumina left)

6) iron free surface layer (gamma alumina) is approximately $70 \mathrm{~nm}$ thick

\section{Thermodynamics}

In order to investigate and separate the thermodynamic factors which might be controlling the amount of thermally enhanced marker mixing for oxide marker systems into alumina, we examined several sets of samples with markers that had different thermodynamic phase relationships with alumina. These were: $\mathrm{Fe}_{2} \mathrm{O}_{3}$, which has a wide solid solution range and compound formation, and for which we had previously shown that a high temperature regime exists where there is thermally activated radiation enhanced mixing; $\mathrm{Y}_{2} \mathrm{O}_{3}$, which has compound formation; $\mathrm{Cr}_{2} \mathrm{O}_{3}$, which has a complete solid solution range; and $\mathrm{ZrO}_{2}$ which has neither compound formation or solid solubility. The results of the ion beam mixing in these systems and a review of thermodynamic references are shown in Table 2. The marker mixing as a function of temperature is shown in Fig. 5 for all of these systems.

Comparing the behavior of the marker systems with the phase diagram (thermodynamic equilibria), it can be seen that in a system which no compounds or solid solubility exists $\left(\mathrm{ZrO}_{2}\right)$, only ballistic mixing occurs, and as previously seen by Joslin and co-workers [12] [13], de-mixing can occur at high temperatures. In contrast to this, all the systems examined that formed either compounds or solid solutions exhibited high temperature thermally activated ion beam mixing. The highest degree of mixing was observed in the $\mathrm{Fe}_{2} \mathrm{O}_{3}$ system which has both a wide solubility range and compound 
formation. The $\mathrm{Y}_{2} \mathrm{O}_{3}$ and $\mathrm{Cr}_{2} \mathrm{O}_{3}$ systems, which only had compound formation and only solid solution, respectively, also were found to have a thermally enhanced regime, but at much higher temperatures than observed for the $\mathrm{Fe}_{2} \mathrm{O}_{3}$ marker system.

As seen from the TEM study, the difference in marker mixing rate between the amorphous and crystalline matrix cannot be explained by voids in the as-deposited amorphous alumina. The difference can only be attributed to a difference in the initial energy state between the initially fully crystalline matrix material and that of the amorphous material. This difference could be either structural (more two-dimensional surface exposure in the amorphous material), or thermodynamic (higher initial energy state of the amorphous material) which causes easier intercascade diffusion processes, or a combination or both.

\section{Conclusions}

We have shown that the chemical nature of the marker is important in governing the degree of ion beam mixing. This can be seen by comparing the results from the iron metal and the iron oxide marker systems. The cross-section TEM results have shown that the difference in mixing into the amorphous alumina and the crystalline alumina is not due to voids in the amorphous alumina, since voids are not created during the deposition.

\section{Figure Captions}

Figure 1. Typical temperature dependency of ion beam mixed marker spreading for a marker that exhibits thermally enhanced mixing. This example is for iron oxide into amorphous alumina.

Figure 2. Sample configurations for the am/am and am/cryst depositions.

Figure 3(a). RBS spectra for iron metal marker showing very little difference between pre- and post-irradiation marker spreading. 
Figure 3(b). RBS spectra for iron oxide marker in am/am configuration showing significant difference in marker spreading between pre- and post-irradiation conditions. Figure 3(c). Comparison of pre- and post-irradiation RBS spectra for iron oxide marker in am/cryst configuration showing significant marker spreading, and also showing asymmetric mixing profile.

Figure 4(a). TEM cross-section for pre-irradiation am/cryst sample.

Figure 4(b). TEM cross-section for an am/cryst sample ion beam mixed at cryogenic ($145^{\circ} \mathrm{C}$ ) temperatures to a dose of $2.5 \times 10^{16} \mathrm{Ar} / \mathrm{cm}^{2}$.

Figure 4(c). TEM cross-section for an am/cryst sample which was only thermally annealed at high temperature $\left(725^{\circ} \mathrm{C}\right)$.

Figure 4(d). TEM cross-section for an am/cryst sample ion beam mixed at high temperature $\left(625^{\circ} \mathrm{C}\right)$ to a dose of $2.5 \times 10^{16} \mathrm{Ar} / \mathrm{cm}^{2}$.

Figure 5. Summary of results for all thin film oxide marker mixing systems into alumina.

\section{Table Captions:}

\section{Table 1.}

Review of ion mixing results for ceramic systems. Table is divided into three sections: oxide thin markers, oxide bilayers, and other mixing systems (nitrides and carbides).

\section{Table 2.}

Review of thermodynamic aspects and results of marker mixing in alumina.

\section{References}

1. J.W. Mayer and S.S. Lau, in: Surface Modification and Alloying by Laser, Ion, and Electron Beams, eds. J.M. Poate, G. Foti, and D.C. Jacobson (Plenum, N.Y., 1983), p. 241.

2. M. Nastasi and J. W. Mayer, Radiation Effects and Defects in Solids, in press.

3. E.A. Cooper, M. Nastasi, and K. E. Sickafus, Mat. Res. Soc. Symp. Proc. 279, pg 457 (1993). 
4. E. A. Cooper and M. Nastasi, J. Amer. Ceram. Soc., 77 [1], $\tilde{\mathrm{HE}} 268$ (1994).

5. C. J. McHargue, D. L. Joslin, and C. W. White, Nucl. Inst. and Meth. B 91 (1994) 549.

6. A. J. Barcz and M.-A. Nicolet, Appl. Phys. A. 33 (1984) 167.

7. A.J. Barcz, B. M. Paine, and M.-A. Nicolet, Appl. Phys. Lett. 44(1) (1984) 45.

8. B. M. Paine and R. S. Averback, Nucl. Inst. and Meth. B 7/8 (1985) 666.

9. S.-J. Kim, M.-A. Nicolet, R. S. Averback, and D. Peak, Phys. Rev. B.: Condens. Matter, 37 [1] (1988) 38.

10. C.J. McHargue in: Structure-Property Relationships in Surface-Modified Ceramics, eds. C.J. McHargue et. al. (Kluwer, 1989) p. 117.

11. E. A. Cooper and M. Nastasi, Nucl. Inst. and Meth. B 91 (1994) 558.

12. D. L. Joslin, L.J. Romana, C. W. White, C.J. McHargue, P. A. Thévenard, and L.L. Horton, Mat. Res. Symp. Proc. Vol 235 (1992) 351.

13. D.L. Joslin, C. J. McHargue, and C.W. White, Nucl. Inst. and Meth. B 91 (1994) 566.

14. A. G. Balogh, M.-P. Macht, and V. Naundorf, J. Mat. Res. 9[2] (1994) 406.

15. F.L. Freire, Nucl. Inst. and Meth. B 83 (1993) 361.

16. D. W. Lane, Nucl. Inst. and Meth. B 69 (1992) 281.

17. G.C. Farlow, B. R. Appleton, L.A. Boatner, and C.J. McHargue, Mat. Res. Symp. Proc. Vol 45 (1985) 137.

18. D. Fathy, O. W. Holland, J. Narayan and B.R. Appleton, Nucl. Inst. and Meth. B 7/8 (1985) 571.

19. J. Narayan, D. Fathy, O.W. Holland, B. R. Appleton, R.R. Davis, and P.F. Becher, J. Appl. Phys. 56 (1984) 1577.

20. J. E. Pawel, M. Sci. Thesis, U. of Tennessee 1987.

21. R. S. Bhattacharya, A. K. Rai, and P.P. Pronko, J. Mat. Sci. 2 (1987) 211.

22. W. Bolse, S. D. Peteves, A. M. Vredenberg, and F. W. Saris, Nucl. Inst. and Meth. B 64 (1992) 138. 
23. C. W. White, G. Farlow, J. Narayan, G. Clark, and J.E.E. Baglin, Mater. Lett. 2. (1984) 367.

24. T. Corts, A. Traverse, and W. Bolse, Nucl. Inst. and Meth. B 80/81 (1993) 167.

25. E. A. Cooper and M. Nastasi, Appl. Phys. Lett., 64 (22) (1994) 2958.

26. A. Muan, J. Am. Ceram. Soc. 256 (1958) 415; as reproduced as Fig. 2095 of Phase

Diagrams for Ceramists, (Amer. Ceram. Soc. Columbus OH) 1969.

27. D. M. Roy and R. E. Barks, Nature (London), 235[58] (1972) 118, as reproduced as Fig. 5189 of Phase Diagrams for Ceramists, (Amer. Ceram. Soc. Columbus OH) 1981. 28. T. Noguchi and M. Mizuno, Kogyo Kogaku Zasshi, 70[6] (1967) 839, as reproduced as Fig. 4370 of Phase Diagrams for Ceramists, (Amer. Ceram. Soc. Columbus OH) 1978. 29. A. M. Alper in: Science of Ceramics, Vol. 3., Editor: G. H. Stewart (Academic Press, London) (1967) p.339; as reproduced as Fig. 4378 of Pha:. Diagrams for Ceramists, (Amer. Ceram. Soc. Columbus OH) 1975.

\section{DISCLAIMER}

This report was prepared as an account of work sponsored by an agency of the United States wor their Government. Neither the United States Government nor any agency the liability or responsiemployees, makes any warranty, express or implied, or assumes any legal lapparatus, product, or bility for the accuracy, completeness, or usefulness of any information, apparatus, prodecter process disclosed, or represents that its use would not infringe privately owned rights. Reference herein to any specific commercial product, process, or service by trade namerement, recommanufacturer, or otherwise does not necessarily constitute or imply its endorsement, The views mendation, or favoring by the United States Government or any agency seflect those of the and opinions of authors expressed herein do not 
Table 1.

Mixing System (thin marker) Oxides

\begin{tabular}{|c|l|l|l|l|l|l|}
\hline matrix & \multicolumn{1}{|c|}{ oxide marker } & \multicolumn{1}{c|}{ result } & ref & \multicolumn{1}{c|}{ metal marker } & result & ref \\
\hline \multirow{2}{*}{$\mathrm{Al}_{2} \mathrm{O}_{3}$} & $\mathrm{Fe}_{2} \mathrm{O}_{3}$ & $\mathrm{RED}$ & {$[4]$} & $\mathrm{Fe}$ & ballistic & {$[3]$} \\
\cline { 2 - 7 } & $\mathrm{Cr}_{2} \mathrm{O}_{3}, \mathrm{Y}_{2} \mathrm{O}_{3}$ & RED & {$[10]$} & $\mathrm{Y}, \mathrm{Zr}, \mathrm{Ag}$ & ballistic & {$[11]$} \\
\cline { 2 - 7 } & $\mathrm{ZrO}_{2}$ & ballistic, de-mixing & {$[10]$} & $\mathrm{Pt}, \mathrm{Au}, \mathrm{W}, \mathrm{Fe}, \mathrm{Ti}$ & ballistic & {$[6]$} \\
\hline \hline $\mathrm{SiO}_{2}$ & none & $\mathrm{Ti}, \mathrm{Co}, \mathrm{Ni}, \mathrm{Hf}, \mathrm{W}, \mathrm{Pt}, \mathrm{Au}$ & ballistic & {$[7]$} \\
\hline
\end{tabular}

Mixing System (bilayer) Oxides

\begin{tabular}{|c|c|c|c|c|c|c|}
\hline substrate & oxide marker & result & ref & metal marker & result & ref \\
\hline \multirow{2}{*}{$\mathrm{Al}_{2} \mathrm{O}_{3}$} & $\mathrm{Y}_{2} \mathrm{O}_{3}$ & ballistic & {$[12,13]$} & $\mathrm{Cu}$ & ballistic & [14] \\
\hline & $\mathrm{ZrO}_{2}$ & ballistic, de-mixing & {$[12,13]$} & $\mathrm{Cr}$ & ballistic & [15] \\
\hline \multirow{3}{*}{$\mathrm{SiO}_{2}$} & \multirow{3}{*}{ none } & \multirow[t]{3}{*}{-} & \multirow[t]{3}{*}{-} & $\mathrm{Cr}$ & RED & {$[16]$} \\
\hline & & & & $\mathrm{Ti}$ & ballistic & [16] \\
\hline & & & & $\mathrm{Cr}$ & ballistic & [15] \\
\hline
\end{tabular}

Mixing System (bilayer) Nitrides and Carbides

\begin{tabular}{|c|c|c|c|c|c|c|}
\hline substrate & oxide marker & result & ref & metal marker & result & ref \\
\hline \multirow[t]{4}{*}{$\mathrm{SiC}$} & \multirow{4}{*}{ none } & \multirow[t]{4}{*}{-} & \multirow[t]{4}{*}{ - } & $\mathrm{Ni}, \mathrm{Cu}, \mathrm{Cr}, \mathrm{Al}$ & ballistic & [17] \\
\hline & & & & $\mathrm{Ni}$ & ballistic & [18][19] \\
\hline & & & & $\mathrm{Al}$ & ballistic & [20] \\
\hline & & & & $\mathrm{Ti}$ & ballistic & [21] \\
\hline \multirow[t]{2}{*}{$\mathrm{Si}_{3} \mathrm{~N}_{4}$} & $\mathrm{Cr}_{2} \mathrm{O}_{3}$ & ballistic & [22] & $\mathrm{Cr}, \mathrm{Cr} / \mathrm{Si}$ & ballistic & {$[22]$} \\
\hline & & & & $\mathrm{Ni}$ & ballistic & {$[17][23]$} \\
\hline AlN & none & - & - & $\mathrm{Ti}, \mathrm{Cr}, \mathrm{Ni}$ & ballistic & [24] \\
\hline $\operatorname{TiN}$ & none & & & Al & ballistic & [24] \\
\hline $\mathrm{Ni}_{3} \mathrm{~N}$ & none & & & $\mathrm{Al}$ & high level ballistic & [24] \\
\hline
\end{tabular}


Table 2.

\begin{tabular}{|l|l|l|l|l|}
\hline marker & $\begin{array}{l}\text { ion mixing activation energy } \\
(\mathrm{eV})\end{array}$ & ref & compounds or solid solution & ref \\
\hline $\mathrm{Fe}_{2} \mathrm{O}_{3}$ & $\begin{array}{l}0.52 \text { (amorphous) } \\
1.07 \text { (crystalline) }\end{array}$ & $\begin{array}{l}{[4]} \\
{[25]}\end{array}$ & $\begin{array}{l}\mathrm{T}>1400 \mathrm{C} \text { compound: }\left(\mathrm{Fe}, \mathrm{Al}_{4} \mathrm{O}_{6} \text { ( ss spinel) }\right. \\
\mathrm{T}<1400 \mathrm{C} \mathrm{Al} \mathrm{O}_{3} \text { solid solution with } \mathrm{Fe}_{2} \mathrm{O}_{3}\end{array}$ & {$[26]$} \\
\hline $\mathrm{Cr}_{2} \mathrm{O}_{3}$ & 0.36 & {$[11]$} & $\begin{array}{l}\text { complete solid solution } \mathrm{Cr}_{2} \mathrm{O}_{3} \text { in } \mathrm{Al}_{2} \mathrm{O}_{3} \text { for all } \\
\mathrm{T}<\mathrm{Tm} \text { to }<20 \% \mathrm{Cr}_{2} \mathrm{O}_{3}\end{array}$ & {$[27]$} \\
\hline $\mathrm{Y}_{2} \mathrm{O}_{3}$ & 0.25 & {$[11]$} & compounds: $\mathrm{Y}_{3} \mathrm{Al}_{5} \mathrm{O}_{12}, \mathrm{Y}_{4} \mathrm{Al}_{2} \mathrm{O}_{9}$ & {$[28]$} \\
\hline $\mathrm{ZrO}_{2}$ & - & {$[11]$} & none & {$[29]$} \\
\hline
\end{tabular}


Temperature $\left({ }^{\circ} \mathrm{C}\right)$

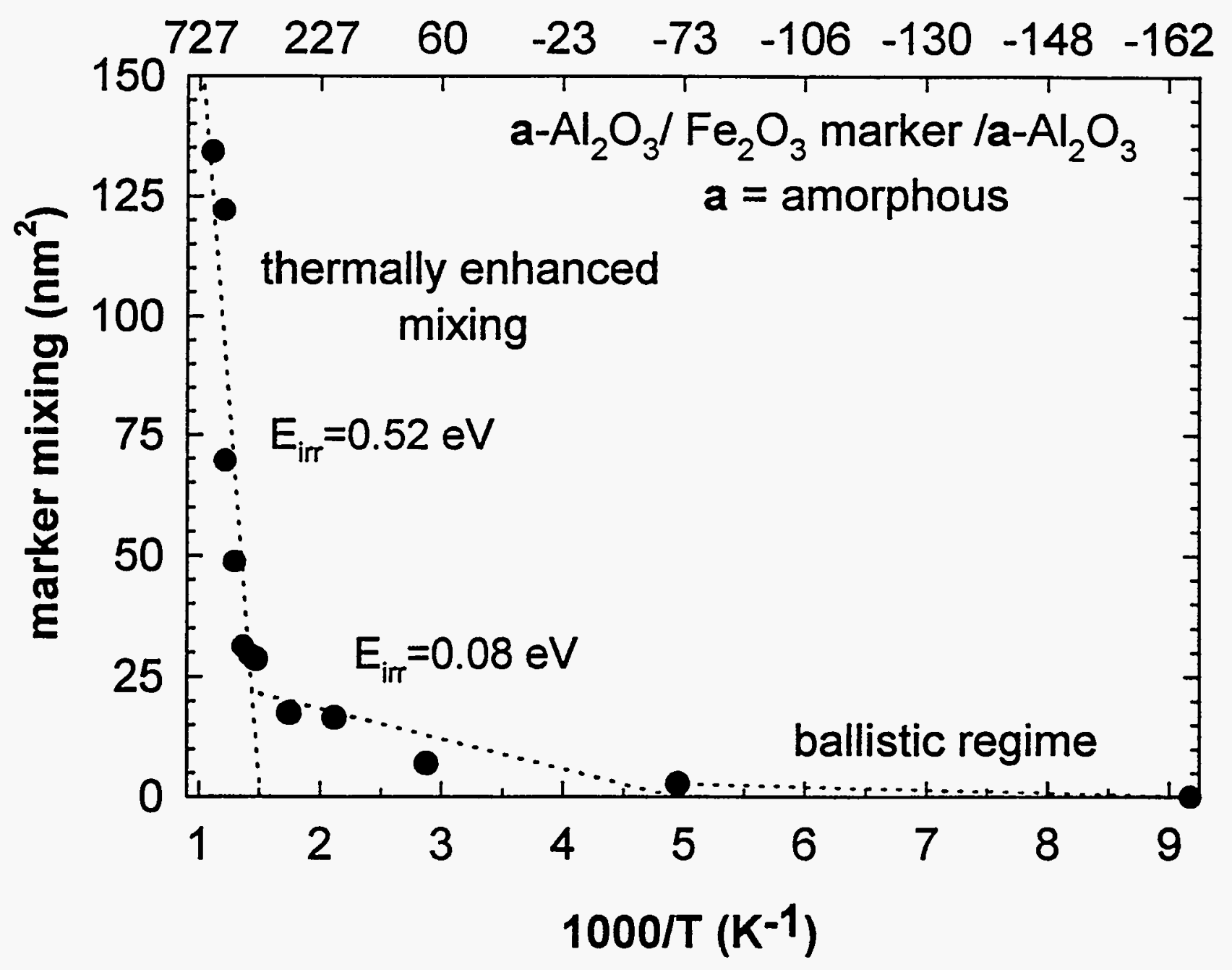


(a)

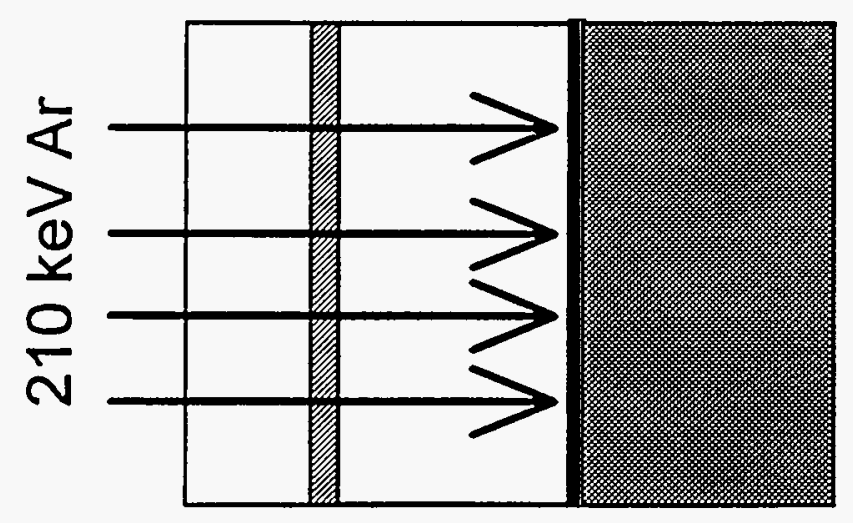

a- $\mathrm{Al}_{2} \mathrm{O}_{3} / \mathrm{Fe}_{2} \mathrm{O}_{3} / \mathrm{a}-\mathrm{Al}_{2} \mathrm{O}_{3} / \mathrm{Pt} /$ sapphire (am/am configuration)

(b)

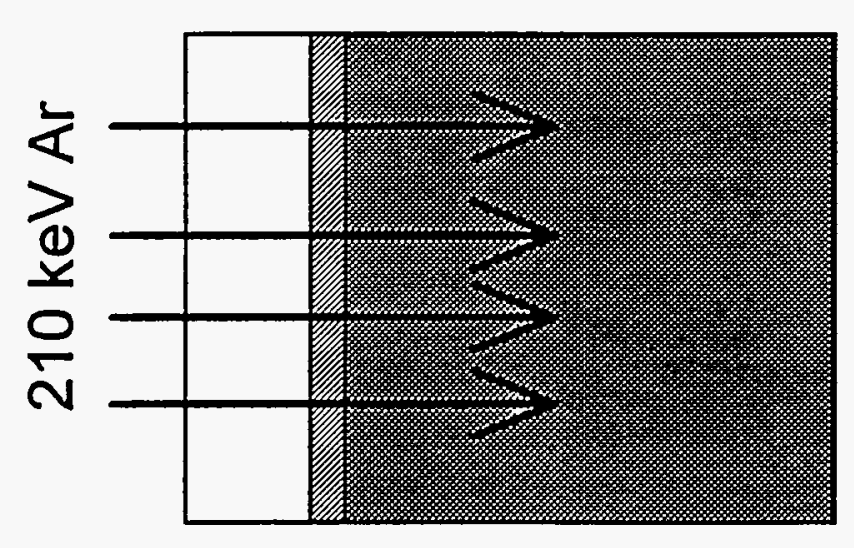

a- $\mathrm{Al}_{2} \mathrm{O}_{3} / \mathrm{Fe}_{2} \mathrm{O}_{3} /$ sapphire (am/cryst configuration)

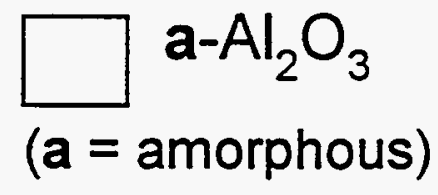

$\mathrm{Fe}_{2} \mathrm{O}_{3}$

$\mathrm{Pt}$

sapphire

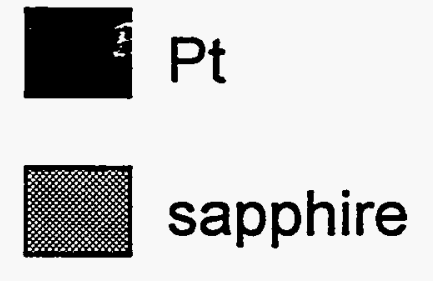




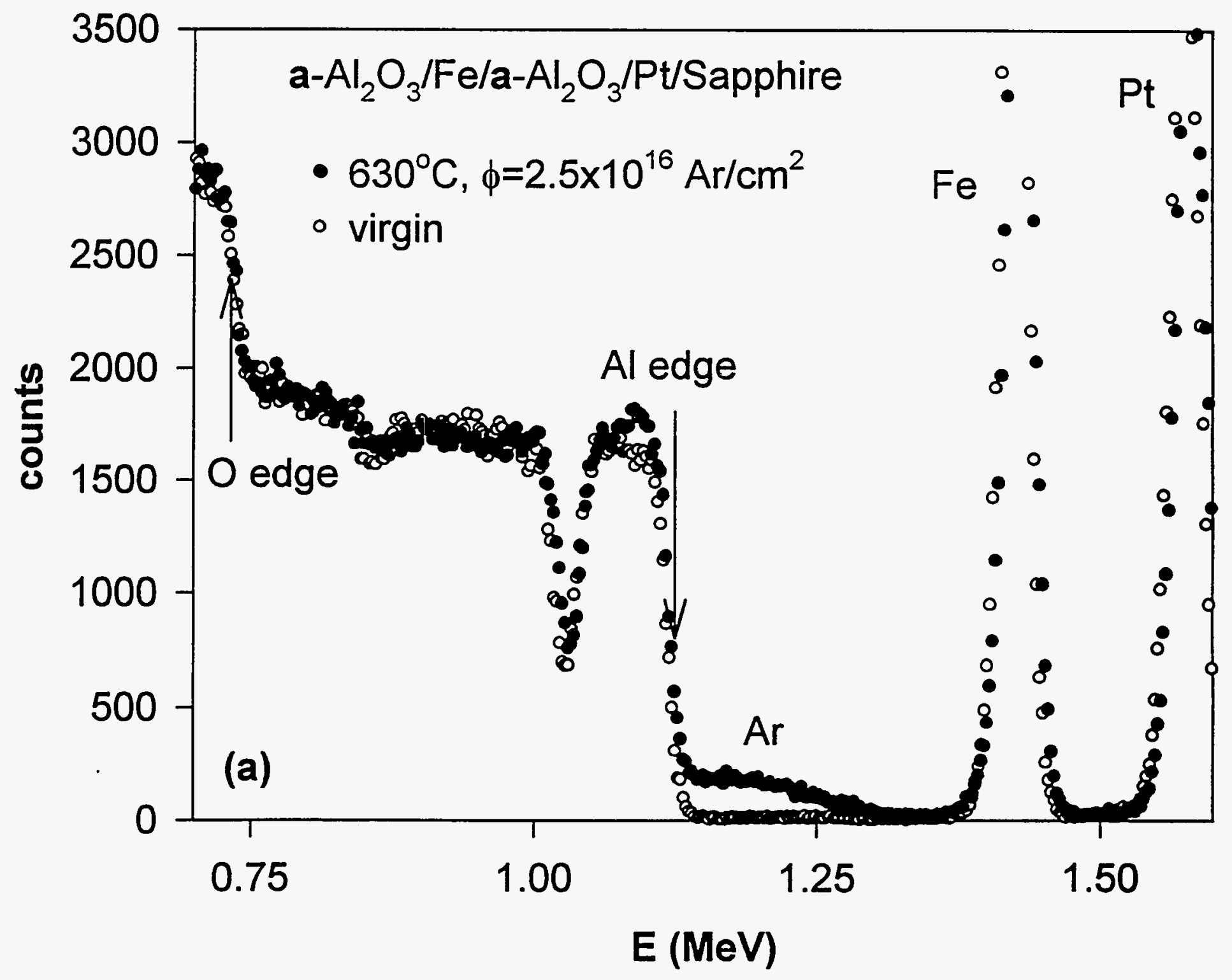




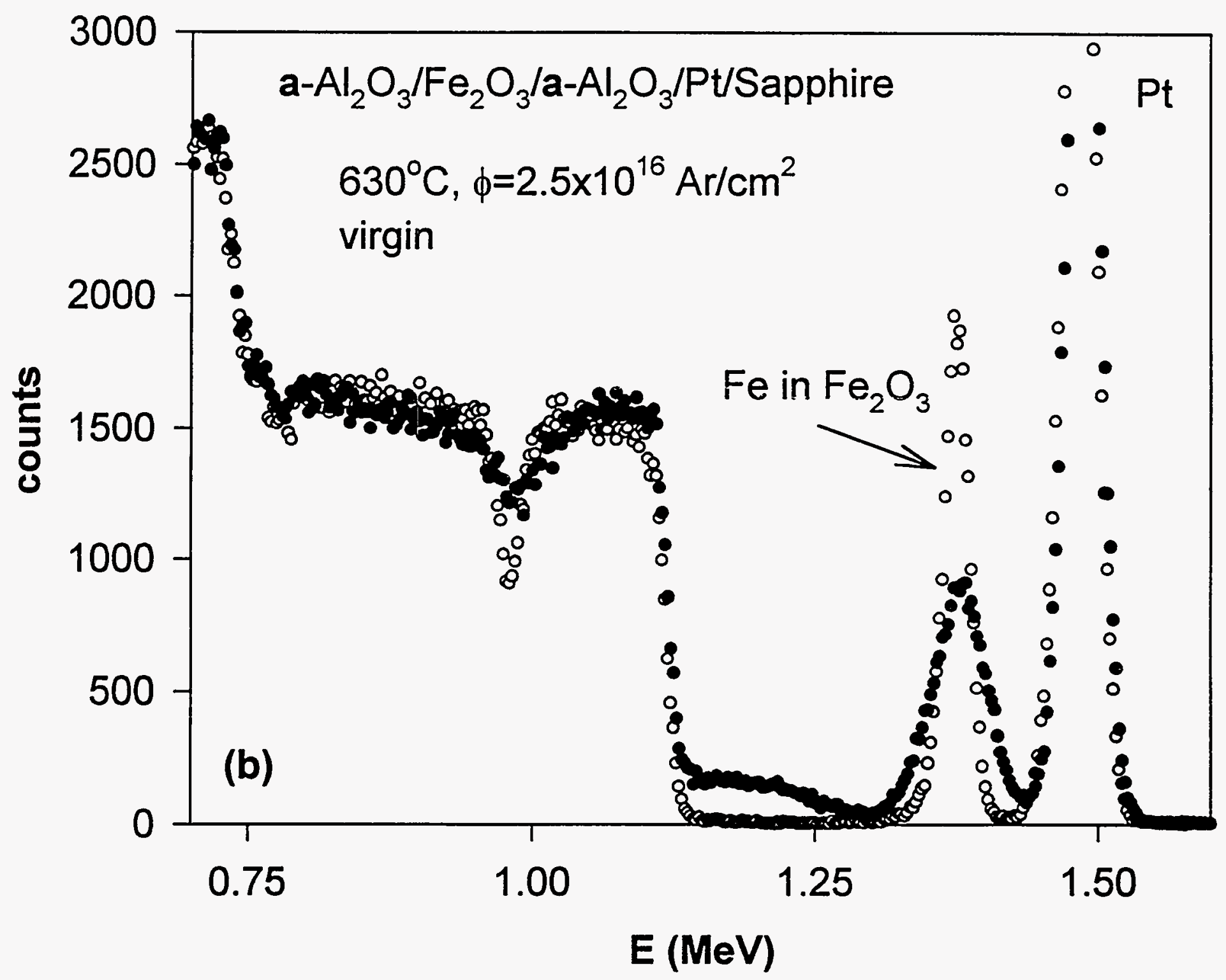




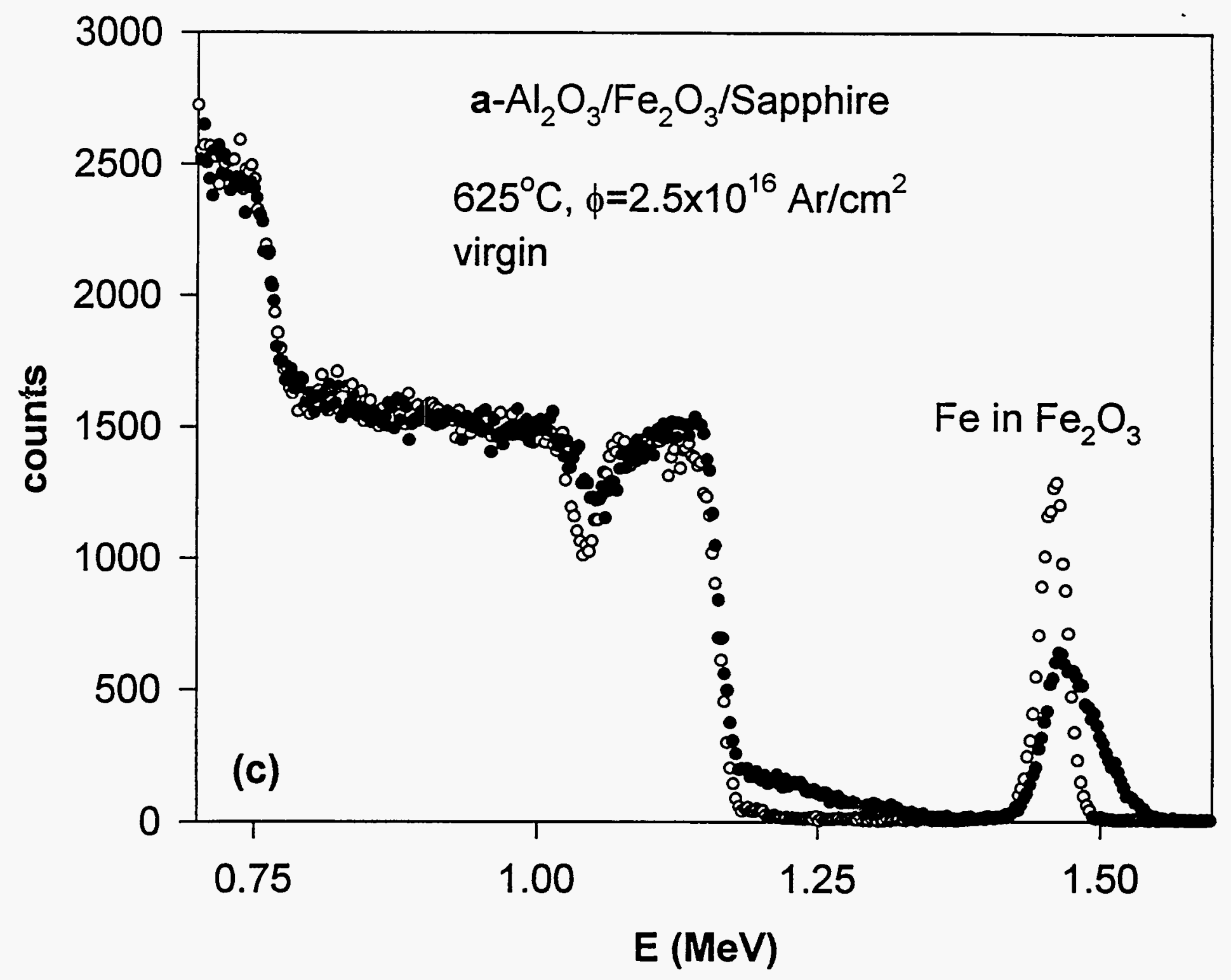




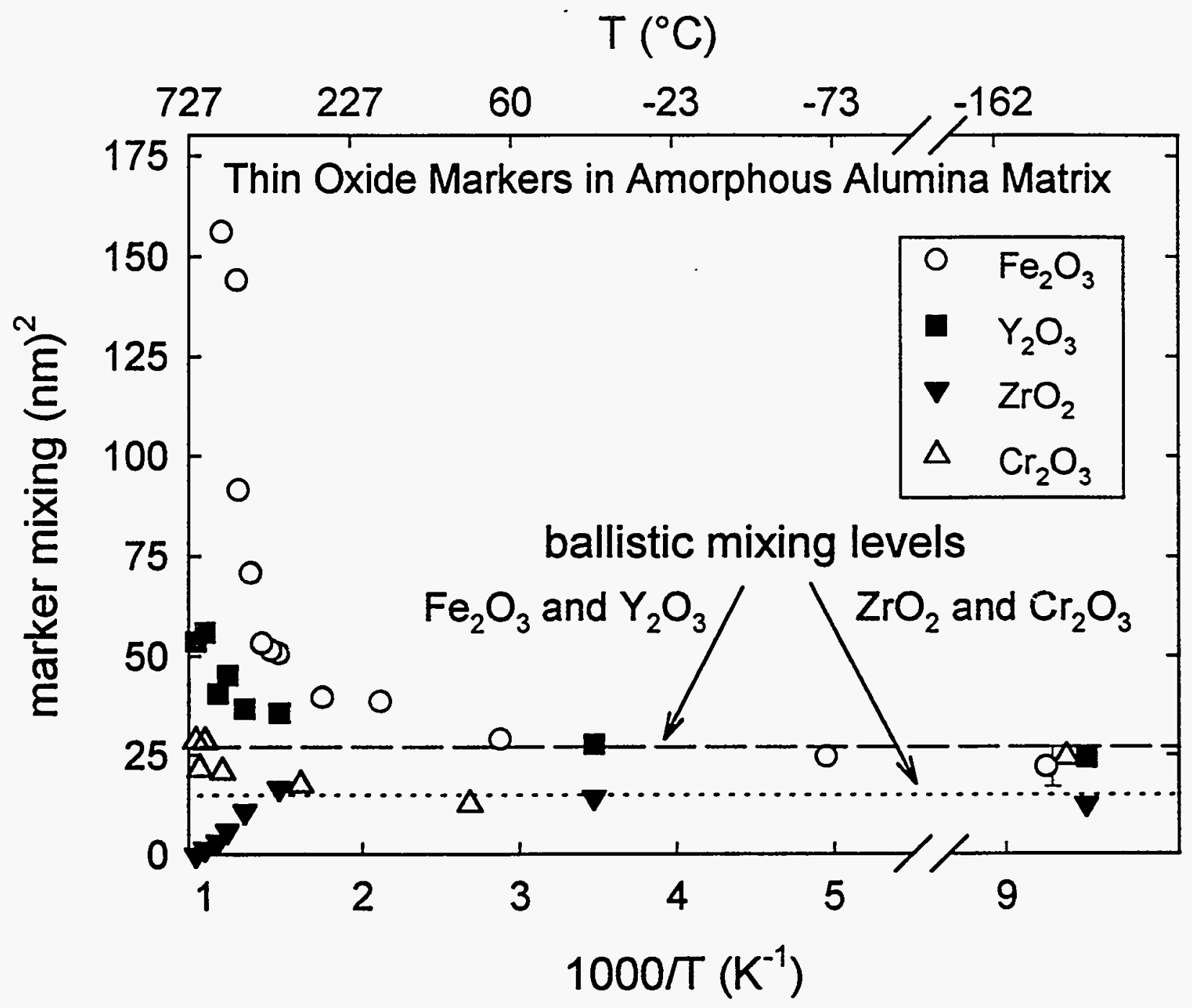

